\title{
Ultrathin barium titanate films by polyol thermal decomposition process
}

\author{
Hyeong Seok Lee • Sang Man Koo • \\ Jung Whan Yoo
}

Received: 3 June 2010/ Accepted: 19 August 2010/Published online: 2 September 2010

(c) The Author(s) 2010. This article is published with open access at Springerlink.com

\begin{abstract}
We have successfully fabricated barium titanate $\left(\mathrm{BaTiO}_{3}\right)$ films on $\mathrm{Si}(100)$ and $\mathrm{Pt}(111) / \mathrm{Ti} / \mathrm{SiO}_{2} / \mathrm{Si}$ substrates using the polyol thermal decomposition (PTD) process by spin-coating technique. In PTD process, we confirmed that the crystalline oxycarbonate $\mathrm{Ba}_{2} \mathrm{Ti}_{2} \mathrm{O}_{5} \mathrm{CO}_{3}$ films were directly formed as a consequence of evaporation of polyol precursor solution prepared simply by mixing metal chlorides and ethylene glycol, and then converting them into crystalline $\mathrm{BaTiO}_{3}$ films through thermal decomposition at $>500{ }^{\circ} \mathrm{C}$. This feature makes it possible to grow densely packed and crack-free $\mathrm{BaTiO}_{3}$ films as thin as $70 \AA$ per cycle. Although PTD is described here for a complex metal-oxide film of $\mathrm{BaTiO}_{3}$, other simple and complex metal-oxide thin films with high-dielectric constant materials are also likely to be suitable for deposition with accurate control of film thickness and composition using the polyol precursor solutions.
\end{abstract}

Metal-oxide thin films, such as $\mathrm{AO}$ and $\mathrm{ABO}_{3}$, are important components in a wide array of electronic and optical devices, and their study and manufacture involve major aspects of current science and technology [1]. The ability to deposit and tailor reliable metal-oxide films (with a particular recent emphasis on ultrathin systems) is indispensable for contemporary solid-state electronics. Many

H. S. Lee $(\bowtie) \cdot$ J. W. Yoo

Eco-Composite Materials Center, Korea Institute of Ceramic Engineering and Technology, 233-5, Gasan-Dong,

Geumcheon-Gu, Seoul 153-801, Korea

e-mail: chemhslee@hotmail.com

H. S. Lee · S. M. Koo

Department of Chemical Engineering, Hanyang University, Haengdang-dong, Seongdong-Gu, Seoul 133-791, Korea different methods are used to make these thin films, such as various physical and chemical vapor depositions mainly dependent on vacuum deposition techniques, and many new techniques have been developed [1-3]. However, the use of these vacuum deposition techniques, the high cost of necessary equipment, and restriction of coatings on a relatively small area have limited their potential applications [4]. On the other hand, chemical solution depositions (CSD) such as sol-gel and metallo-organic decomposition (MOD) are more cost-effective, but many metal oxides cannot be deposited, and the control of stoichiometry is not always possible owing to differences in chemical reactivity among the metals [5]. In particular, precise control of film thickness, crystallinity, and morphology are significant problems to be overcome in CSD [6].

One of the challenges in solution-based processes of complex metal-oxide films has been to produce high-quality films with desired chemical composition. The sol-gel method among the CSD processes is one of the most important approaches, which are being extensively used for the fabrication of complex oxide thin films. The sol-gel method show attractive advantages due to the fact that films with extremely uniform composition over large areas can be obtained from chemical solution deposition [7]. A key issue of any CSD thin films processing is the chemistry of precursor solution, which governs the properties of the final oxide layer. Even more challenging for sol-gel processing of complex metal-oxides is the identification of a solvent system in which the multiple organometallic precursors are reciprocally compatible. Recently, a few attempts have been reportedly made to add polymer during the sol preparation to increase the critical film thickness without cracks, and to modify the mechanical properties of the resulted films [5].

In this article, we introduce a novel method to grow the metal-oxide films using the "polyol thermal decomposition" 
(PTD) process, which is a simple methodology to enable accurate control of film thickness and composition by the spin-coating technique. To demonstrate the generality of the method, we describe the production of barium titanate $\left(\mathrm{BaTiO}_{3}\right)$ as a complex metal-oxide film, which is of interest for applications in electro-optic devices [8], multilayer ceramic capacitor (MLCC) $[9,10]$, tunable microwave devices [11, 12], and high-density dynamic random access memories (DRAMs) $[13,14]$. In PTD process, we used a mixture of polyol precursor solution of metal chlorides (i.e., $0.2 \mathrm{M}$ of barium chloride $\left(\mathrm{BaCl}_{2} \cdot 2 \mathrm{H}_{2} \mathrm{O}\right.$, Showa, $\left.99 \%\right)$ and $0.2 \mathrm{M}$ of titanium tetrachloride $\left(\mathrm{TiCl}_{4}\right.$, Aldrich, $\left.99.9 \%\right)$ with sparingly soluble metal salts in water) with deionized water and ethylene glycol as a solvent under ambient conditions without the need for refluxing to grow the $\mathrm{BaTiO}_{3}$ film. The preparation of polyol precursor solution is similar to the polyol process [15, 16], using diol or polyalcohol (for example, ethylene glycol or glycerol) as a solvent to reduce metal salts to metal particles, and the Pechini process $[17,18]$, except that citric acid or other chelating agents are not utilized. The polyol precursor solution also ensures a homogeneous metal distribution and prevents unwanted reaction that can lead to the formation of undesired phases. This solution can remain stable for months even when multiple metals are used.

In the deposition process reported here, the polyol precursor solution is applied onto a substrate and then spincoated at 3,000 rpm for $30 \mathrm{~s}$. When the coated substrate was heated at adequate temperature in ambient conditions, the solvent of the polyol precursor solution is immediately evaporated and then deposited into the crystalline intermediate phases (correspondingly small film volume) with desired metal species on the substrate surface, which enable the growth of the metal-oxide films through thermal decomposition. In contrast, the conventional sol-gel process deposits the amorphous gel films, which cause cracking or pore collapses due to the large weight loss and shrinkage under heat treatment and thicker films [5, 7]. The major distinction between the PTD and the existing sol-gel or CSD processes is that the deposited film is not amorphous gel but intermediate crystal with small volatile carbonate species. Therefore, we have successfully grown either continuous simple or complex metal-oxide films as thin as $\sim 10 \mathrm{~nm}$ by spin coating using PTD process. These spin-coating cycles can be repeated to build up thicker films. The latter feature makes it possible to grow relatively thinner and crack-free metal-oxide films that are difficult to prepare by sol-gel or CSD.

We examine the evaporation for the polyol precursor solution of $\mathrm{BaTiO}_{3}$ and characterization of crystalline thin films based on these solutions. As seen in Fig. 1, the weight loss in the temperature region up to $700{ }^{\circ} \mathrm{C}$ investigated by Thermodynamic gravimetric analysis (TGA) is about

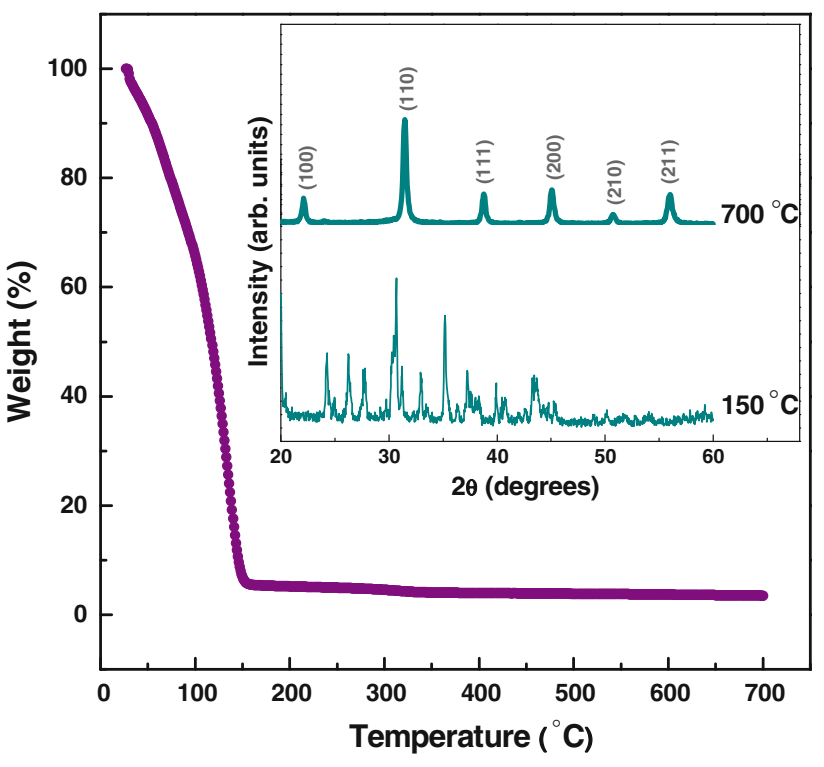

Fig. 1 Thermodynamic gravimetric analysis (TGA) for the polyol precursor solution. Inset: the powder X-ray diffraction pattern for the precursor after a TGA run terminated at two temperatures (between baking at $150{ }^{\circ} \mathrm{C}$ and annealing at $700{ }^{\circ} \mathrm{C}$ ). The crystallinity was measured by X-ray diffractometer with $\mathrm{Cu} \mathrm{K} \alpha(\lambda=1.54056 \AA)$ radiation (Rikagu D/Max P/N: $3 \mathrm{~kW} / 40,45 \mathrm{~mA}$ )

97.4\% of the initial sample weight, but mostly occurs below $\sim 150{ }^{\circ} \mathrm{C}$ (about $92.7 \%$ ), which was attributed to loss of solvents with ethylene glycol and water. There is no appreciable weight loss beyond $150{ }^{\circ} \mathrm{C}$. Remarkably, we observe that the solvents of ethylene glycol with aqueous metal chloride solution have been evaporated below $\sim 150{ }^{\circ} \mathrm{C}$, ultimately leading to crystalline thin films. In the inset of Fig. 1, we also show the powder X-ray diffraction patterns for the polyol precursor solution after a TGA run terminated at two temperatures (between baking at $150{ }^{\circ} \mathrm{C}$ and annealing at $700{ }^{\circ} \mathrm{C}$ ). The as-baked product at $150{ }^{\circ} \mathrm{C}$ is found to be in crystalline $\mathrm{Ba}_{2} \mathrm{Ti}_{2} \mathrm{O}_{5} \mathrm{CO}_{3}$ intermediate phase [19-23]. As the annealing temperature increased, the peaks of the crystalline intermediate phases formed at $150{ }^{\circ} \mathrm{C}$ decreased by thermal decomposition and then the peaks of the polycrystalline $\mathrm{BaTiO}_{3}$ begins to form when annealed above $500{ }^{\circ} \mathrm{C}$ with weak diffraction peaks for the intermediate phase (not shown in figure). The XRD patterns annealed at $700{ }^{\circ} \mathrm{C}$ for $1 \mathrm{~h}$ are composed of cubic $\mathrm{BaTiO}_{3}$ structure with lattice parameters $\left(\mathrm{BaTiO}_{3}\right.$ : $a=3.996 \AA$ ).

In the case of $\mathrm{BaTiO}_{3}$, the formation mechanism from solution-derived precursor is complicated and has been argued for a long time [24]. Considering the general formation mechanism, it has been reported that $\mathrm{BaTiO}_{3}$ forms either by a nucleation process at the $\mathrm{BaCO}_{3} / \mathrm{TiO}_{2}$ interface or through a decomposition of crystalline $\mathrm{Ba}_{2} \mathrm{Ti}_{2} \mathrm{O}_{5} \mathrm{CO}_{3}$ intermediate phase [19-23]. The first of them proposed that the solution-derived metal organic precursors decompose 
to form a finely divided mixture of $\mathrm{BaCO}_{3}$ and $\mathrm{TiO}_{2}$, which subsequently reacts to form $\mathrm{BaTiO}_{3}$ on heating at $600-700{ }^{\circ} \mathrm{C}$ [20]. Alternatively, it has been proposed that $\mathrm{BaTiO}_{3}$ is formed directly through thermal decomposition of crystalline intermediate phases of the oxycarbonate $\mathrm{Ba}_{2} \mathrm{Ti}_{2} \mathrm{O}_{5} \mathrm{CO}_{3}[19,20,23]$ above $600{ }^{\circ} \mathrm{C}$, in which it can be clearly identified as mainly those appearing at $2 \theta=21.3^{\circ}$, $24.6^{\circ}, 26.8^{\circ}, 28.2^{\circ}, 29.3^{\circ}, 30.36^{\circ}, 32.3^{\circ}, 34.1^{\circ}, 41.1^{\circ}, 44.9^{\circ}$, and $54.4^{\circ}[22,23]$. From the XRD data (Fig. 1, inset), the as-baked film at $150{ }^{\circ} \mathrm{C}$ is consistent with neither diffraction peaks of the mixture of $\mathrm{BaCO}_{3}$ and $\mathrm{TiO}_{2}$ [21] nor amorphous phase but corresponding to diffraction peaks of the oxycarbonate $\mathrm{Ba}_{2} \mathrm{Ti}_{2} \mathrm{O}_{5} \mathrm{CO}_{3}$. We therefore mentioned that the intermediate phase formed at $150{ }^{\circ} \mathrm{C}$ is the oxycarbonate $\mathrm{Ba}_{2} \mathrm{Ti}_{2} \mathrm{O}_{5} \mathrm{CO}_{3}$ crystals. The oxycarbonate $\mathrm{Ba}_{2} \mathrm{Ti}_{2} \mathrm{O}_{5} \mathrm{CO}_{3}$ crystal is metastable, since it always decomposed to $\mathrm{BaTiO}_{3}$ with increasing temperature or prolonged heating at a fixed temperature [20]. In PTD process, we found that the oxycarbonate $\mathrm{Ba}_{2} \mathrm{Ti}_{2} \mathrm{O}_{5} \mathrm{CO}_{3}$ crystals (correspondingly small film volume and volatile carbonate species) were directly formed as a consequence of evaporation of polyol precursor solution, before the formation of $\mathrm{BaTiO}_{3}$ through thermal decomposition process.

Ultrathin $\mathrm{BaTiO}_{3}$ films per cycle were spin coated onto silicon or Pt-coated substrates from the polyol precursor solution. The spin-coated film was then immediately backed in air for $2 \mathrm{~min}$ at about $150{ }^{\circ} \mathrm{C}$ on a preheated hot plate. Final annealing/decomposition treatments were in air at $700{ }^{\circ} \mathrm{C}$. Transmission electron microscope (TEM) image of the cross-section of a device demonstrates the ultrathin, crystalline nature of the film, with average film thickness of $\sim 70 \AA$. One representative high-resolution TEM image from $\mathrm{BaTiO}_{3}$ film is also shown as an inset to Fig. 2a which displays clear lattice fringes; the distance between the fringes matches well with $\mathrm{BaTiO}_{3}(4.0 \AA)$. An AFM image of the $\mathrm{BaTiO}_{3}$ film deposited per cycle (Fig. 2b) also shows a densely packed particle layer completely covering the surface. The films per cycle have very smooth surface as shown by AFM image (Fig. 2b: r.m.s. roughness $=0.45 \mathrm{~nm}$ for $\mathrm{a} \mathrm{BaTiO}_{3}$ film with about $\sim 70 \AA$ thick). From the AFM image, it can be seen that the deposited $\mathrm{BaTiO}_{3}$ film per cycle has a smooth surface with a small grain size over conformal coverage.

The deposition rate and the surface morphology of the $\mathrm{BaTiO}_{3}$ films grown by PTD process onto the silicon substrates at $700{ }^{\circ} \mathrm{C}$ for $1 \mathrm{~h}$ in each spin coating cycle was monitored by ellipsometry and scanning electron micrograph (SEM). As shown in Fig. 3a, the film thickness deposited in 40 cycles grew linearly with the number of cycles, demonstrating that the same deposition thickness occurs in each PTD cycle. The average increase in film thickness per cycle is about $\sim 70 \AA$ for $\mathrm{BaTiO}_{3}$ films. In
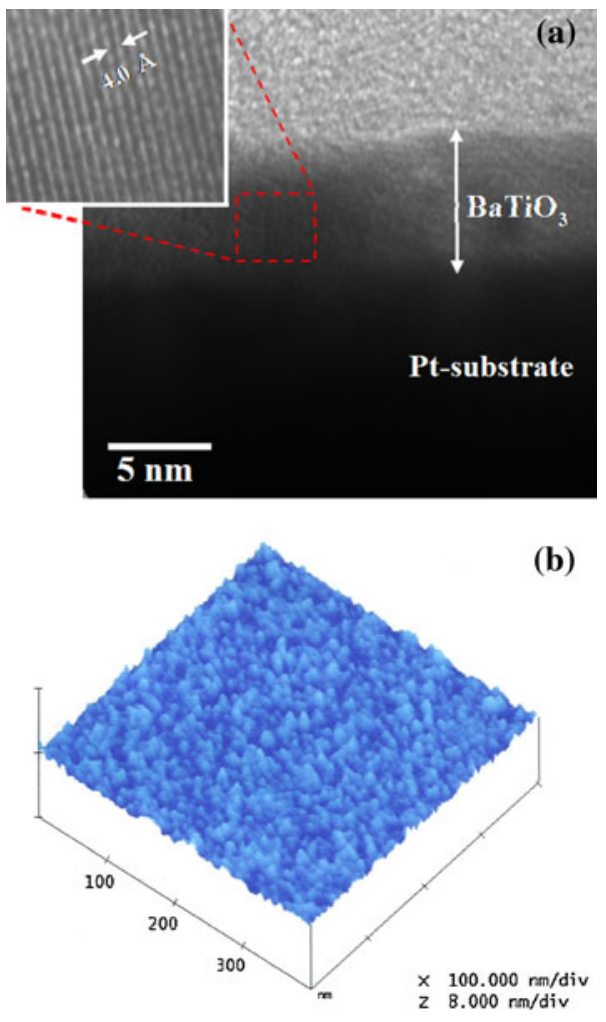

Fig. 2 a The cross-sectional TEM image of $\mathrm{BaTiO}_{3}$ thin film deposited with one cycle by PTD on $\mathrm{Pt}(111) / \mathrm{Ti} / \mathrm{SiO}_{2} / \mathrm{Si}$ substrate after annealing at $700{ }^{\circ} \mathrm{C}$ for $1 \mathrm{~h}$ in ambient atmosphere. Inset: HRTEM image of the $\mathrm{BaTiO}_{3}$ thin film deposited with one cycle showing clear lattice fringes. b AFM image obtained after deposition of one cycle (the lateral dimensions are $400 \times 400 \mathrm{~nm}$ )

particular, continuous crystalline perovskite films as thin as $70 \AA$ can be formed by spin-coating technique using the PTD process. The thickness deposited in 40 cycles can also be visualized by a cross-sectional SEM (Fig. 3a, inset), which formed a $\mathrm{BaTiO}_{3}$ film of nearly 290-nm thickness. Figure $3 \mathrm{~b}$ shows an AFM image of a $\mathrm{BaTiO}_{3}$ film deposited at $700{ }^{\circ} \mathrm{C}$ for $1 \mathrm{~h}$ in 40 cycles and characterized by a surface roughness with a uniform, densely packed and crack-free microstructure, which is in agreement with the SEM images (Fig. 3c). The average size and surface roughness of the densely packed spherical-shaped grains were close to $40-60 \mathrm{~nm}$ and $3.4 \mathrm{~nm}$, respectively. It can be, therefore, described that the oxycarbonate $\mathrm{Ba}_{2} \mathrm{Ti}_{2} \mathrm{O}_{5} \mathrm{CO}_{3}$ crystals (corresponding to small film volume) deposited through evaporation of polyol precursor solution on the substrate probably contributes to the high quality of the resulting $\mathrm{BaTiO}_{3}$ films and the ability to achieve ultrathin dimensions. The microcracks in amorphous gel films usually emerged from the conventional sol-gel-processed films. One of the explanations for microcrack formation in sol-gel-derived films is the condensation reaction and pore collapse in amorphous gel films under heat treatment [5]. However, in this PTD 


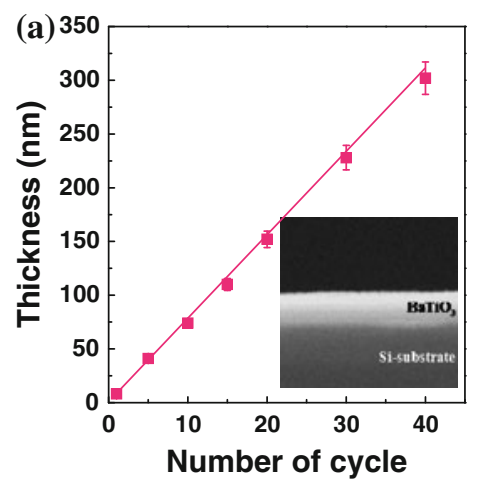

Fig. 3 The growth rate and surface morphology for $\mathrm{BaTiO}_{3}$ film deposited from 1 to 40 cycles at $700{ }^{\circ} \mathrm{C}$. a The linear relationship between $\mathrm{BaTiO}_{3}$ film thickness on silicon substrate and the number of deposition cycles. Inset: cross-sectional scanning electron micrograph

process, because the oxycarbonate $\mathrm{Ba}_{2} \mathrm{Ti}_{2} \mathrm{O}_{5} \mathrm{CO}_{3}$ crystals were decomposed to the $\mathrm{BaTiO}_{3}$ crystals by a small volatile carbonate species on the substrate without the condensation reaction in amorphous gel films, it is also possible to grow densely packed and crack-free $\mathrm{BaTiO}_{3}$ films.

Using the PTD process, we developed $\mathrm{BaTiO}_{3}$ film of about $200 \mathrm{~nm}$ at $700{ }^{\circ} \mathrm{C}$ for $1 \mathrm{~h}$ in 30 cycles on $\mathrm{Pt} / \mathrm{Ti} / \mathrm{SiO}_{2} /$ $\mathrm{Si}$ substrate. The X-ray diffraction patterns of the $\mathrm{BaTiO}_{3}$ film are shown in Fig. 4a. Apart from the substrate peaks, the peaks of (100), (110), (200), and (211) were observed, indicating that the phase-pure $\mathrm{BaTiO}_{3}$ film is obtained. In particular, it can be seen that $\mathrm{BaTiO}_{3}$ thin film derived from the PTD process exhibited a perovskite phase of a (110) preferred orientation. In order to fabricate $\mathrm{a} \mathrm{BaTiO}_{3}$ capacitor structure, a platinum top electrode was deposited at room temperature using the sputtering with a shadow mask. The area of the top electrode was $1 \times 10^{-4} \mathrm{~cm}^{2}$. The dielectric constant and the dissipation factor of a $\mathrm{BaTiO}_{3}$ capacitor was measured as a function of frequency. As shown in Fig. 4b, the dielectric constant and the dissipation factor at $1 \mathrm{GHz}$ are about 160 and 0.015 , respectively. Similar dielectric measurement results have been reported for $\mathrm{BaTiO}_{3}$ thin films prepared by the sol-gel technique. The dielectric constant of the $\mathrm{BaTiO}_{3}$ capacitor slightly decreases with increasing frequency. There are no sudden changes in the dielectric constant and the dissipation factor within the frequency range up to $1 \mathrm{GHz}$.

In conclusion, we have successfully fabricated barium titanate $\left(\mathrm{BaTiO}_{3}\right)$ films on $\mathrm{Si}(100)$ and $\mathrm{Pt}(111) / \mathrm{Ti} / \mathrm{SiO}_{2} / \mathrm{Si}$ substrates using the polyol thermal decomposition (PTD) process by spin-coating technique. In PTD process, we confirmed that the crystalline oxycarbonate $\mathrm{Ba}_{2} \mathrm{Ti}_{2} \mathrm{O}_{5} \mathrm{CO}_{3}$ films were directly formed as a consequence of evaporation of polyol precursor solution, prepared simply by mixing metal chlorides and ethylene glycol, and then converting them into crystalline $\mathrm{BaTiO}_{3}$ films through thermal with 40 cycles on silicon substrate. b Tapping-mode AFM image obtained after deposition of 40 cycles (the lateral dimensions are $1.0 \times 1.0 \mu \mathrm{m})$. c The scanning electron microscopy image obtained after deposition of 40 cycles
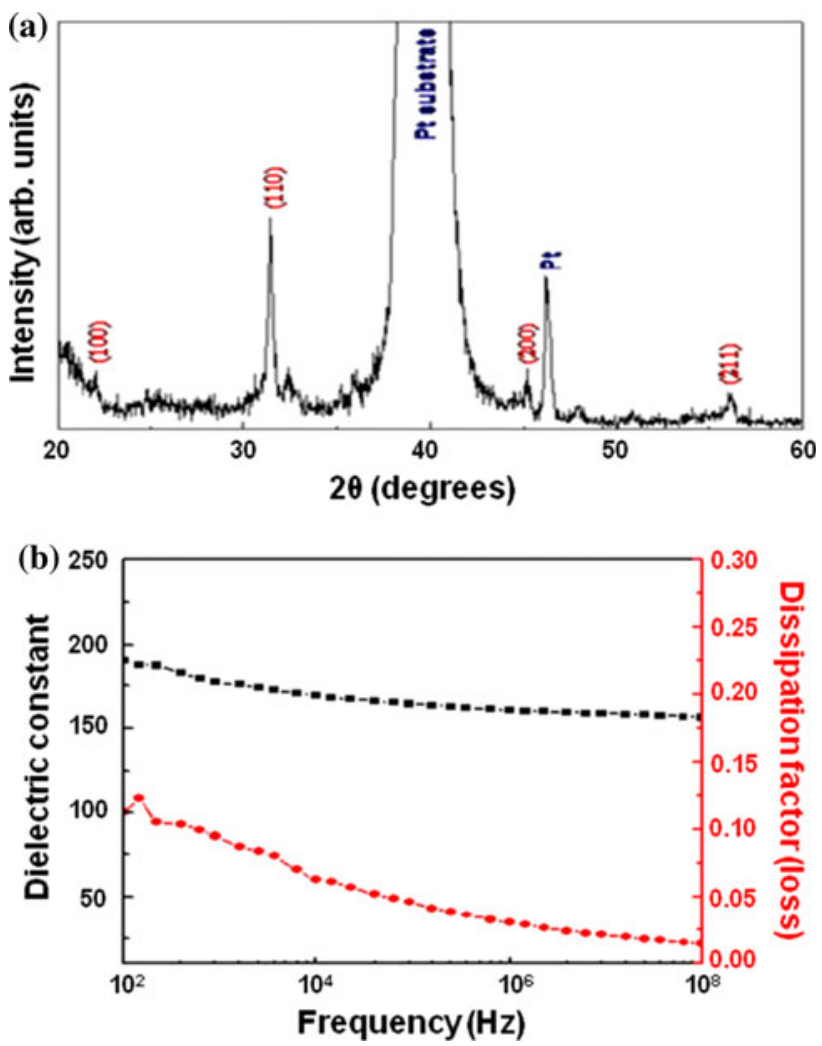

Fig. 4 a The X-ray diffraction pattern of $\mathrm{BaTiO}_{3}$ thin film deposited with 30 cycles by $\mathrm{PTD}$ onto $\mathrm{Pt}(111) / \mathrm{Ti} / \mathrm{SiO}_{2} / \mathrm{Si}$ substrate after annealing at $700{ }^{\circ} \mathrm{C}$ for $1 \mathrm{~h}$ in ambient atmosphere. b Dielectric constant and dissipation factor (loss) for $\mathrm{Pt} / \mathrm{BaTiO}_{3} / \mathrm{Pt} / \mathrm{Ti} / \mathrm{SiO}_{2} / \mathrm{Si}$ films as a function of frequency at room temperature. The crystallinity of $\mathrm{BaTiO}_{3}$ thin film was measured by X-ray diffractometer with $\mathrm{Cu}$ $\mathrm{K} \alpha(\lambda=1.54056 \AA)$ radiation

decomposition at $>500{ }^{\circ} \mathrm{C}$. This feature makes it possible to grow densely packed and crack-free $\mathrm{BaTiO}_{3}$ films as thin as $70 \AA$ per cycle. Although PTD is described here for a complex metal-oxide film of $\mathrm{BaTiO}_{3}$, other simple and complex metal-oxide thin films with high-dielectric 
constant materials are also likely to be suitable for deposition with accurate control of film thickness and composition using the polyol precursor solutions.

Open Access This article is distributed under the terms of the Creative Commons Attribution Noncommercial License which permits any noncommercial use, distribution, and reproduction in any medium, provided the original author(s) and source are credited.

\section{References}

1. Park SM, Clark BL, Keszler DA, Bender JP, Wager JF, Reynolds TA, Herman GS (2002) Science 297:65

2. Mitzi DB, Kosbar LL, Murray CE, Copel M, Afzali A (2004) Nature 428:299

3. Hausmann D, Becker J, Wang S, Gordon RG (2002) Science 298:402

4. Gao Y, Masuda Y, Peng Z, Yonezawa T, Konmoto K (2003) J Mater Chem 13:608

5. Jia QX, Mccleskey TM, Burrell AK, Lin Y, Collis GE, Wang H, Li ADQ, Foltyn SR (2004) Nat Mater 3:529

6. Kovtyukhova NI, Buzaneva EV, Waraksa CC, Martin BR, Mallouk TE (2000) Chem Mater 12:383

7. Tian HY, Luo YG, Pu XH, He XY, Qiu PS, Ding AL (2001) Mater Chem Phys 69:166

8. Zeng J, Wang H, Wang M, Shang S, Wang Z, Lin C (1998) Thin Solid Films 322:104
9. Tsuyumoto I, Kobayashi M, Are T, Yamazaki N (2010) Chem Mater 22:3015

10. Devaraju NG, Lee BI, Wang X, Viviani M, Nanni P (2006) J Mater Sci 41:3335. doi:10.1007/s10853-005-5390-1

11. Yang X, Yao X, Zhang L (2004) Ceram Int 30:1525

12. Kaiser DL, Vaudin MD, Rotter LD, Wang JL, Cline JP, Hwang CS, Marinenko RB, Gillen JG (1995) Appl Phys Lett 66:2801

13. Kingon AI, Maria JP, Streiffer SK (2000) Nature 406:1032

14. Lee EJH, Pontes FM, Leite ER, Longo E, Varela JA, Araujo EB, Eiras JA (2000) J Mater Sci Lett 19:1457

15. Sun S, Murray CB, Weller D, Folks L, Moser A (2000) Science 287:1989

16. Sun Y, Xia Y (2002) Science 298:2176

17. Simões AJ, Zaghete MA, Stojanovic BD, Gonzalez AH, Riccardi CS, Cantoni M, Varela JA (2004) J Eur Ceram Soc 24:1607

18. Pechini MP (1967) US Patent 3:330

19. Tian HY, Luo WG, Ding AL, Choi J, Lee C, No K (2002) Thin Solid Films 408:200

20. Kumar S, Messing GL, White WB (1993) J Am Ceram Soc 76:617

21. Kong LB, Ma J, Huang H, Zhang RF, Que WX (2002) J Alloys Compd 337:226

22. Durán P, Capel F, Tartaj J, Gutierrez D, Moure C (2001) Solid State Ionics 141:529

23. Durán P, Gutierrez D, Tartaj J, Bañares MA, Moure C (2002) J Eur Ceram Soc 22:797

24. Marssi ME, Marrec FL, Lukyanchuk IA, Karkut MG (2003) J Appl Phys 94:3307 